\title{
Physical Activity during Pregnancy: Recommendations and Assessment Tools
}

\section{Atividade física durante a gestação: recomendações $e$ ferramentas de avaliação}

\author{
Cibele Santini de Oliveira ${ }^{1}$ Thiago dos Santos Imakawa ${ }^{2}$ Elaine Christine Dantas Moisés ${ }^{1}$ \\ ${ }^{1}$ Department of Gynecology and Obstetrics, Faculty of Medicine of \\ Ribeir Ribeirão ao Preto, Universidade de São Paulo, Ribeirão Preto, \\ SP, Brazil \\ 2 Faculty of Medicine of Ribeirão Preto, Universidade de São Paulo, \\ Ribeirão Preto, SP, Brazil

\begin{abstract}
Address for correspondence Elaine Christine Dantas Moisés, MD, PhD, Departamento de Ginecologia e Obstetrícia do Hospital das Clínicas - $8^{\circ}$ andar, Faculdade de Medicina de Ribeirão Preto, Universidade de São Paulo, Av Bandeirantes 3900 - Campus da USP, 14049-900 - Ribeirão Preto, SP, Brazil (e-mail: elainemoises@fmrp.usp.br).
\end{abstract}

Rev Bras Ginecol Obstet 2017;39:424-432.

\begin{abstract}
Keywords

- physical exercise questionnaire

- physical activity

- evaluation

- pregnancy

Resumo
Palavras-chave
- questionário de exercício físico
- atividade física
- avaliação
- gravidez

The literature that supports and recommends the practice of exercise during pregnancy is extensive.However, although a more complete research on ways to evaluate the physical activity performed by pregnant women has been perfomed, it is found that there is no gold standard and that the articles in the area are inconclusive. Thus, the objective of the present article is to review relevant aspects, such as, technique and applicability of the different methods for the assessment of physical activity during pregnancy to provide more reliable and safe information for health professionals to encourage their pregnant patients to engage in the practice of physical activity. This review concluded that all tools for the analysis of physical activity have limitations. Thus, it is necessary to establish the objectives of evaluation in an appropriate manner, as well as to determine their viability and costeffectiveness for the population under study.

A literatura que apoia e recomenda a prática do exercício durante a gravidez é extensa. Apesar disso, embora tenha sido feita uma pesquisa mais completa sobre as formas de avaliar a atividade física realizada por mulheres grávidas, verifica-se que não há padrão ouro, e que os artigos na área são inconclusivos. Assim, o objetivo do presente artigo é revisar aspectos relevantes, como a técnica e a aplicabilidade dos diferentes métodos de avaliação da atividade física durante a gestação, a fim de fornecer aos profissionais de saúde informações mais confiáveis e seguras para encorajar as pacientes grávidas à prática de atividade física. Esta revisão concluiu que todas as ferramentas para a análise da atividade física têm limitações. Assim, é necessário estabelecer os objetivos da avaliação de forma adequada, bem como determinar a sua viabilidade e custoefetividade para a população em estudo.
\end{abstract}

received

December 4, 2016

accepted

May 4, 2017
DOI https://doi.org/

10.1055/s-0037-1604180.

ISSN 0100-7203.
Copyright $\odot 2017$ by Thieme Revinter

Publicações Ltda, Rio de Janeiro, Brazil
License terms

(c) $(1) \$$ 


\section{Introduction}

The benefits of physical exercise during pregnancy for both mother and fetus have been reported in the literature. ${ }^{1,2}$ However, a reduction of physical activity is frequently observed during this period in the life of a woman, motivated by both popular beliefs in the contraindication of its practice and by the interference of factors such as age, ethnicity, schooling and socioeconomic level. ${ }^{3,4}$

This review will describe the main tools available to assess the level of physical activity for pregnant women and thus, it can contribute to greater confidence of health professionals in recommending the practice of physical activity to their patients.

\section{Background Considerations}

Some concepts need to be established for an appropriate understanding of the physiological and pathophysiological basis of the use of parameters for the assessment of physical activity during pregnancy, as indicated below.

- Physical activity can be defined as any body movement produced by the contraction of skeletal muscles. ${ }^{5}$

- Physical exercise is defined as physical activity consisting of the execution of planned, structured and repetitive body movements with the objective of improving physical fitness. ${ }^{5}$

- Sport can be defined as "an institutionalized competitive activity involving vigorous physical effort or the use of relatively complex motor skills." ${ }^{\prime 6}$

\section{Types}

Several types of physical exercises can be practiced by pregnant women, although, in general, they are divided into three major categories: aerobic exercises aiming at gaining strength and involving more expressive cardiovascular adaptations, resistance exercises mainly performed to obtain muscle hypertrophy and strength, and stretching exercises that cause an increased muscle fiber size, thus improving flexibility. ${ }^{2}$ Within aerobic exercises, bicycle ergometer pedaling, swimming, dancing, using an arm ergometer, walking, and climbing stairs are the modalities more commonly practiced during pregnancy. Regarding resistance exercises, resistance can be offered with weights, elastic tapes, springs, or manual resistance. ${ }^{7}$

\section{Benefits}

In general, regular exercise has been shown to improve conditioning, to reduce the muscle skeletal complaints habitually related to pregnancy, to provide well-being, to improve body image, and to reduce maternal weight gain. In addition, regular physical activity during pregnancy improves or maintains physical conditioning, helps control weight gain and provides psychological well-being. ${ }^{8}$

Depending on its type, frequency and intensity, the practice of physical exercise during pregnancy can also improve cardiovascular function by reducing heart rate and blood pressure, even with increased volume and cardiac output both during rest and during exercise itself. ${ }^{9}$ Additional advan- tages are improved pulmonary function with an increase in peak flow, reduction of the anaerobic threshold and, improved oxygen uptake $\left(\mathrm{O}_{2}\right) ;{ }^{10}$ reduced risk of developing gestational diabetes due to the increase in insulin affinity for its cell receptor with a consequent decrease in insulin resistance; ${ }^{11}$ a lower risk of developing gestational hypertension and preeclampsia; $;^{1,12}$ a lower weight gain and a reduced risk of obesity $;^{13}$ improved muscle conditioning due to both strength gain and improved flexibility; ${ }^{2}$ increased sensation of wellbeing; reduction of anxiety; improved self-esteem; reduced risk of depression; ${ }^{13}$ improved quality of sleep, greater disposition throughout the day, increased motivation to exercise; improvement of physical discomfort that may occur during pregnancy; prevention and reduction of low back pain; reduction of edema in the extremities. ${ }^{2}$ In addition, there are reports of an equilibrated increase in fetal growth, ${ }^{14}$ a reduced duration of labor, a lower necessity of cesarean delivery, a lower incidence of obstetrical complications, ${ }^{15}$ a lower risk of preterm delivery, ${ }^{3}$ and a lower risk of neonatal complications. ${ }^{13}$

\section{Risks and Contraindications}

As postulated by the American College of Gynecology and Obstetrics, the National Institute for Health and Care Excellence and the Canadian Society of Gynecology and Obstetrics, the risks of practicing moderate physical activity during pregnancy are minimal, involving neither maternal injuries, nor fetal growth or development. In addition, exercise does not interfere with lactation when practiced during the puerperal period. ${ }^{8,16}$ Thus, sedentary pregnant women with no gestational complications should be encouraged to practice physical activity to maintain a healthy life. ${ }^{16}$

Starting from the second trimester of pregnancy, some precautions should be taken during the practice of physical activity. It is recommended to avoid the supine position during the exercises, since it may cause difficulties in venous return with a consequent decrease of cardiac output and an increased risk of orthostatic hypotension. ${ }^{8}$

The situations that can determine the discontinuation of physical activity are vaginal bleeding, resting dyspnea, dizziness, headache, precordial pain, calf swelling, and muscle weakness affecting equilibrium. ${ }^{8}$

Contraindications considered to be relative are: severe anemia, maternal cardiac arrhythmia that is not monitored, heart disease with hemodynamic repercussions, asthma, restrictive lung disease, decompensated type 1 diabetes, morbid obesity, severe malnutrition (BMI below $12 \mathrm{~kg} / \mathrm{m}^{2}$ ), an extremely sedentary lifestyle, intrauterine growth restriction, orthopedic limitation, severe smoking, and uncontrolled hypothyroidism, nephropathy, unconscious hypoglycemia, and neuropathic dysautonomia. $8,17,18$

There are also obstetric situations that are considered absolute contraindication of physical exercise such as: isthmocervical incompetence, cerclage, multiple gestation pregnancy with risk of preterm delivery, persistent bleeding in the second and third trimesters, placenta previa before 26 weeks of gestational age, preterm labor during the current pregnancy, premature chorioamniorhexis and, hypertensive syndromes of pregnancy. 8,18 


\section{Recommendations about the Practice of Physical Activity during Pregnancy}

Most women benefit from the practice of physical activity, with few risks when practicing it during the various phases of life. During a gravidic cycle of habitual risk, that is, not associated with clinical or obstetrical complications, women should be stimulated to pratice aerobic and muscle strengthening exercises. A complete clinical evaluation is necessary for the recommendation of a program of physical exercises and its implementation to guarantee that the patient does not present any contraindications. ${ }^{8}$

Current recommendations regarding the practice of physical activity are based on the norms of the American College of Sports Medicine, which state that physical activity should be performed for at least 30 minutes daily at moderate intensity, preferably 5 times a week or for a total of 150 minutes per week, avoiding more than 2 consecutive days without physical activity. ${ }^{17,19,20}$ It is also indicated the combination of aerobic physical activity with resistance physical activity, at least twice a week, with the execution of at least five exercises involving large muscle groups in each session. ${ }^{20}$

During a pregnancy considered to be of habitual risk, the activities listed here are considered to be safe for initiation or continuation, with the need of adaptation in some modalities due to the physiological changes occurring during this period and to the fetal necessities: walking, swimming, stationary bike, aerobic activities of low impact, modified yoga and pilates (avoiding positions that result in decreased venous return and hypotension), racquet sports (avoiding very rapid movements that might affect equilibrium, thus increasing the risk of falls), running and resistance training for women who were already practicing these activities before they became pregnant and who are under medical monitoring. ${ }^{8}$

On the other hand, the following activities should be avoided during the gestational period: contact sports such as ice hockey, boxing, soccer and basketball, activities involving a high risk of falls such as water skiing, surfing, cycling, horse riding, diving and sky diving, hot yoga or hot pilates. ${ }^{8}$

Among the main fundamentals of physical activity during pregnancy, it is important to point out that: ${ }^{21}$ women who did not exercise routinely before pregnancy should start with no more than 15 minutes of continuous exercise 3 times a week, gradually increasing the daily sessions to 30 minutes; women who did exercise routinely before pregnancy can maintain their exercise routine without the occurrence of adverse effects; recreational exercises such as swimming or fast walking and exercises for the conditioning of muscle strength are safe and beneficial; the objective of recreational exercise is to keep in shape and not to increase physical fitness.

\section{Methods for the Assessment of Physical Activity}

\section{Indirect Methods: Self-report Instruments}

With their good acceptability and practicality, questionnaires are one of the subjective forms of assessments most frequently used in epidemiological studies. ${ }^{22}$ This concept is applicable to the analysis of the impact of physical activity on the pre- conceptional, gestational and puerperal periods, permitting data collection in large samples by means of this tool.

For these reasons, most of the studies designed to identify the predictors of participation in physical activities during pregnancy are based on self-reported assessment. Since these studies are used to elaborate interventions that can be planned to increase physical activity during or before pregnancy, it is fundamental that the conclusions reached be valid and reliable. ${ }^{23}$

The disadvantages of questionnaires are that they involve subjective measures of low reliability since they may overestimate the levels of physical activity compared with objective measures such as those obtained with an accelerometer or pedometer. ${ }^{24,25}$

The adoption of the system elaborated by Sternfeld and Goldman-Rosas (2012), ${ }^{26}$ consisting of the 10 questions listed below, can be of help in the choice of the instrument for the assessment of physical activity that best satisfies the objectives of the examiner: what is the primary objective of the study or program?; what is the design of the study?; what are the hypotheses of the study?; what is the physical activity or sedentary behavior to be measured?; which domains of physical activity need to be measured?; which parameters of physical activity or sedentary behavior need to be assessed?; should nonspecific physical activities be assessed or can they be categorized?; what is the summary measure desired of physical activity or sedentary behavior?; which is the target public?; what are the important logistic constraints?

To assess physical activity among pregnant women it is necessary to use a questionnaire validated for this phase of a woman's life, since the instruments elaborated for nonpregnant women or for men may be less sensitive to differences in the levels of activity among pregnant women. These questionnaires may include activities that cannot be adapted to the gravidic period or may omit low intensity activities, at times inappropriately classifying pregnant women as sedentary rather than active. ${ }^{27}$

Since women spend more time on occupational activity and household and family care tasks and, less time on leisure or conditioning activities, to dimension the physical activity of women in an objective manner it is necessary to use an assessing instrument that contains such activities. ${ }^{28}$

\section{- Physical Activity Readiness Medical Examination (PARMed-X)}

This instrument is part of a program for pregnant women developed by the Canadian Society for Exercise Physiology and validated by using peak oxygen consumption. ${ }^{29}$

This tool classifies recreational physical activity into different levels according to its intensity, frequency and duration (-Table 1). Individuals who practice physical activity at a frequency of less than once or twice a week and for a period of time of less than 20 minutes have a zero index of physical activity and therefore, are considered to be unfit. Those who practice physical activity once to twice a week for 20 minutes, or more than twice a week for less than 20 minutes have a physical activity index of one and are considered to be active. Finally, individuals who perform physical activity more than 
Table 1 Classification into recreational physical activity levels according to the physical activity readiness medical examination $(\text { PARMed-X) })^{29}$

\begin{tabular}{|l|l|l|l|}
\hline $\begin{array}{l}\text { Levels of } \\
\text { recreational } \\
\text { physical activity }\end{array}$ & $\begin{array}{l}\text { Physical } \\
\text { activity } \\
\text { index }\end{array}$ & $\begin{array}{l}\text { Frequency } \\
\text { (times/week) }\end{array}$ & $\begin{array}{l}\text { Time } \\
\text { (minutes) }\end{array}$ \\
\hline Unfit & 0 & $<1-2$ & $<20$ \\
\hline Active & 1 & $1-2$ & $=20$ \\
\cline { 2 - 4 } & 1 & $>2$ & $<20$ \\
\hline Fit & 2 & $>2$ & $>20$ \\
\hline
\end{tabular}

twice a week for more than 20 minutes are considered to be fit and have a physical activity index of two.

Advantage - it permits the classification of recreational physical activity, which serves as a parameter for the recommended prescription of physical activity.

Disadvantages - difficult validation, since the cost of the measurement of oxygen consumption (VO2) limits its practice in small centers and in places without the appropriate structure; limited applicability to populations with a low index of recreational activity and, there are few reports about this instrument in the literature, requiring the need of more studies for the analysis of its applicability.

\section{- Pregnancy Physical Activity Questionnaire (PPAQ)}

In view of the need for an instrument that could be applied to pregnant women, in 2004, Chasan-Taber et al $^{30}$ elaborated and validated for the English language a short, easily understood and self-administered questionnaire denoted Pregnancy Physical Activity Questionnaire (PPAQ), which intended to assess the level of physical activity specifically in pregnant women. The PPAQ was first elaborated to become an instrument of worldwide applicability that would determine the practice of physical activity in populations of pregnant women. ${ }^{30}$ This instrument is an adaptation to the population of pregnant women of the International Physical Activity Questionnaire developed by the World Health Organization. ${ }^{31}$

The activities selected for the PPAQ permit the establishment of the relationship between type of physical activity and energy expenditure (EE) for each participant. This approach prioritizes the ability of the questionnaire to classify the subjects into activity quartiles in a correct manner, in addition to eliminating the need for unnecessarily long instruments. ${ }^{27}$ The PPAQ proposes the measurement of the level of physical activity during the participation of a subject in 33 activities (-Table $\mathbf{2}$ ).

As response options, the PPAQ proposes a time scale in relation to the daily situations questioned: none, less than 30 minutes per day, 30 minutes to 1 hour per day, 1 to 2 hours per day, 2 to 3 hours per day, 3 hours or more per day.

According to the recording of type of physical activity, intensity, duration, frequency and, consequently, metabolic equivalent (MET) rate, each woman is classified in terms of practice of physical activity into one of four categories during the last trimester ( - Table 3 )..$^{30}$
Table 2 Types of activity and number of questions per item of the pregnancy physical activity questionnaire (PPAQ)

\begin{tabular}{|l|l|}
\hline Type of activity & Number of questions \\
\hline Household chores/care & 12 \\
\hline Occupational activities & 5 \\
\hline Exercise/sports & 9 \\
\hline Transportation/displacement & 3 \\
\hline Inactivity/sedentarism & 4 \\
\hline
\end{tabular}

There are smaller versions of this questionnaire with a smaller number of questions taking into consideration the reality of the population to which it is administered. ${ }^{32}$

Advantages - it takes into account small activities that are important for EE but that are usually neglected; ${ }^{30}$ it was translated and validated for various countries; ${ }^{30,33,34}$ this questionnaire has been found to be reliable for the measurement of physical activity in pregnant women with different intensities of obesity and can be used as a tool to detail physical activity. ${ }^{35}$

Disadvantages - the questionnaire is imprecise regarding self-reported physical activity, a fact that may generate inflated estimates of its validity. ${ }^{27}$

\section{- Kaiser Physical Activity Survey (KPAS)}

This is a questionnaire based on the Baecke et $\mathrm{al}^{36}$ physical activity research and was specifically projected for the assessment of physical activity in women.

This instrument evaluates the multiple domains of physical activity (domestic activity/caregiver, occupational, active life and sports/exercises) and, although similar to the PPAQ in structure, its objective is to measure the types of physical activity performed by women and not their EE or their level of physical activity. The KPAS provides an encompassing assessment of each activity domain, and can be more useful for studies in which physical activity is the primary outcome. ${ }^{27}$ The questions of the KPAS are grouped into four blocks, as can be seen in - Table $4 .^{27}$

Activity indices are calculated for each activity domain by adding the specific categorical responses and dividing their sum by the number of items, with mean values ranging from one to five.

Table 3 Classification into groups according to exercise intensity and its correspondence to metabolic equivalents (METs)

\begin{tabular}{|l|l|}
\hline Classification & Correspondence to METs \\
\hline Sedentary & $<1.5$ \\
\hline Mild & 1.5 to $<3.0$ \\
\hline Moderate & $3.0-6.0$ \\
\hline Vigorous & $>6.0$ \\
\hline
\end{tabular}


Table 4 List of specific activities assessed by the Kaiser Physical Activity Survey ${ }^{27}$

\begin{tabular}{|l|l|l|}
\hline Block & Type of activity & Number of items \\
\hline 1) Household chores/ family care & $\begin{array}{l}\text { House cleaning, shopping, gardening, care of elderly persons and } \\
\text { children, construction work. }\end{array}$ & 11 \\
\hline 2) Occupational activities & $\begin{array}{l}\text { working activities in the sitting and standing positions, walking } \\
\text { while carrying weights, efforts that cause transpiration. }\end{array}$ & 11 \\
\hline 3) Life habits & $\begin{array}{l}\text { Watching television, riding a bicycle or walking to go to work or to } \\
\text { school. }\end{array}$ & 4 \\
\hline $\begin{array}{l}\text { 4) Participation in } \\
\text { sports and exercises }\end{array}$ & $\begin{array}{l}\text { The frequency and duration of up to three sports or exercises } \\
\text { performed periodically are included. }\end{array}$ & 15 \\
\hline
\end{tabular}

Advantages - the KPAS investigates a larger number of activities than the PPAQ. ${ }^{27}$

Disadvantages - the data do not reflect expenditure in MET, impairing their comparison to other questionnaires; ${ }^{27}$ few studies are available about the use of this questionnaire for pregnant women. ${ }^{37}$

\section{Objective Measures}

Several movement sensors have been developed to measure in a more objective manner the physical activity performed during a determined period of time. ${ }^{38}$ The applicability of these tools at assistance centers is impaired by the fact that they need training to be used, and proximity of the patient for data collection, with a higher cost compared with questionnaires. ${ }^{24}$

Other measures of objective assessment are calorimetry, physiological markers, and direct observation and monitoring of heart rate parameters. ${ }^{24}$ These devices can be used as instruments for the validation of the reports of the subjects investigated. 24,39

Each direct measure has its own limitation and there is no "gold standard" for the determination of physical activity. ${ }^{24,40}$ The choice of the tool to be used depends on a series of factors such as the specific element of physical activity that is interested in measuring, the necessary precision of the measurement, the target population of interest, and the cost and logistic of the measurements. ${ }^{39}$

\section{- Pedometer/Step counter}

This is a small device of low cost that can be used attached to the clothes of the person on the hip or at any other convenient site to count each step of the individual along the day. ${ }^{41,42}$ The first commercial versions of the device were based on gear-driven mechanical technology and were produced to measure the distance covered, although with low precision. ${ }^{43}$ Pedometers with microelectromechanical systems, whose data are processed by an algorithm, are available today. The device has a horizontal pendulum with a spring lever that moves up and down with vertical accelerations to measure the total number of steps. When the arm of the lever is shifted above a given threshold it determines an electric contact with a sensor that records the step. ${ }^{39,44}$

Pedometers first became available as self-monitoring tools for the promotion of a life style directed at the practice of physical activity. Pedometers provide a valuable response regarding the steps taken, the distance covered, the time spent in the activity, and an estimate of EE. 42,45

This device provides the rate of steps/day as a standard measure for the assessment of physical activity, facilitating its direct comparison in different studies. ${ }^{25,46}$ Thus, it is being used as a measuring tool by athletes in physical conditioning training programs. ${ }^{47-49}$ The pedometer has also been included as a component of broader health promotion programs, which also associates other strategies such as activities based on the characteristics of the population, physical exams for health control and healthier dietary proposals. ${ }^{42}$ The use of this device in these programs is based on the fact that the visual response of cumulative step count is immediate, leading to an increased perception on the part of an individual of how his behavior affects his physical activity. It is indicated as a self-monitoring mechanism as part of a goal setting process, in addition to providing minute-to-minute information and thus helping to fulfill the objectives of physical activity. ${ }^{45}$

Advantages - characteristics of motivation end encouragement of physical activity since it shows the number of steps taken by a person; ${ }^{46,50,51}$ in adults, it is possible to correlate the increase of 2000 steps/day with the reduction of body mass index (BMI) and blood pressure. ${ }^{41}$

Disadvantages - inability to provide estimates of moderate to vigorous physical activity; ${ }^{25}$ presence of a substantial error in predicting EE in MET; ${ }^{46}$ the prescription of physical activity to young people is compromised since the device does not provide information about the intensity of physical activity; ${ }^{45}$ impossibility to record activities that do not involve walking; ${ }^{45}$ inability to measure non-ambulatory activities, posture or EE and dependence on specific algorithms for the determination of number of steps and, precision is compromised in slow walking (less than $2 \mathrm{rpm}){ }^{52}$

\section{- Accelerometer}

The accelerometer is a device to be attached to the hip, calves or wrists that permits to monitor the frequency, intensity and duration of the episodes of physical activity by means of direct measurements of body accelerations and decelerations. ${ }^{53,54}$ Some types of accelerometers present sensitivity of movement detection on different planes, although most of them are uniaxial, that is, they are sensitive to movement only on the vertical axis. Even accelerometers 
that are sensitive to acceleration on the anteroposterior and/ or lateral plane (biaxial or triaxial) have sensors that are more sensitive to movement on the vertical plane, thus being fundamentally uniaxial. ${ }^{55,56}$

They have a microelectromechanical system that can record gravitational accelerations, which can be calibrated and converted to measurements of oxygen consumption. ${ }^{39}$ Laboratory investigations have established a linear relationship between the measurements recorded by the accelerometer and the $\mathrm{O} 2$ volume consumed (VO2). This permits to relate these data to EE during locomotion and to develop equations for the prediction of MET level and, consequently to determine the classification of the intensity of physical activity into mild, moderate, strong or vigorous. ${ }^{38,43}$

The most diffuse accelerometer is the Actigraph, followed by the Tracmor. ${ }^{55}$ After the first version of the Actigraph, more than 15 different regression equations were developed to estimate EE. ${ }^{38,54,57}$ In general, the regression equations developed to record if a person is standing still or is moving may slightly overestimate the EE of locomotion and of light exercise while greatly underestimating the EE of activities of moderate intensity. In contrast, regression equations developed by using daily life activities of moderate intensity provide more precise estimates of EE for this type of activity, although they may considerably overestimate the EE of sedentary persons and of light activities and underestimate that of vigorous activities. ${ }^{58}$

Advantages - axial and triaxial monitors can record physical activity for long periods of time; ${ }^{59}$ an excellent method for the measurement of daily life activity of pregnant women, such as household chores and child care, also avoiding the problem of counting twice chores that are performed simultaneously. ${ }^{60}$

Disadvantages - there is no standard measurement, impairing the comparison of different studies; the algorithms used are very specific; low sensitivity for physical activities of light intensity or sedentary, inability to differentiate between activities and to measure non-ambulatory activities such as bicycle riding or weight lifting; ${ }^{59}$ technique artifacts may occur in pregnant women due to variation in the positioning of the device according to abdominal size and stomach position in each phase of pregnancy; ${ }^{27}$ the cut-off points needed to calibrate the data of the accelerometer according to specific categories of intensity (light, moderate, strong, and vigorous) have not been calculated for pregnant women. ${ }^{23}$

\section{- Frequency meter}

This is a light device that can be used to estimate the physical activity's EE (PAEE) on the basis of the linear relationship between heart rate (HR) and EE. ${ }^{61}$ The validity and reliability of the frequency meter have not been well determined. ${ }^{62,63}$

The frequency meter is a device consisting of a transducer associated with a data acquisition system placed on the abdominal or wrist region. The sensor system captures, digitizes and stores the HR signal on a full time basis, and calculates the mean for each pre-programmed time range (usually 5 to 15 seconds). Some monitors can store the interbeat interval (IIB series) for several hours, permitting the calculation of instantaneous HR variability. ${ }^{34}$ Heart rate monitoring is an effective objective method used to monitor the intensity, duration and frequency of daily activities using a physiological parameter that detects the cardiovascular adaptation to exercise and estimates energy expenditure. ${ }^{34,63}$

Advantages - the device can measure non-ambulatory activities. $^{34}$

Disadvantages - Heart rate is a poor predictor of EE in the low-intensity range of physical activity and the technique requires calibration of the frequency meter for each individual; since data processing is laborious and time consuming, long periods of use cause electrode wear and may also cause skin irritation; since HR can be altered by other stimuli in addition to physical activity, the device needs to be calibrated for persons who are taking certain medications; ${ }^{64}$ loss of contact and external noise (usually starting at $60 \mathrm{~Hz}$ ) may cause electrical interference with the analysis of the results. These problems can be reduced by appropriate fixation of the sensor to the skin of the user, by the positioning of the transducer close to the system of data acquisition and by the use of an electrolyte gel; ${ }^{65}$ ocurrence of biases in the recordings obtained due to changes in HR not related to exercise; ${ }^{34}$ not usable for the validation of questionnaires. ${ }^{31}$

\section{- Calorimetry}

Energy expenditure can be measured in a precise manner in humans by direct or indirect calorimetry. Since all energy reactions that occur in the organism require oxygen and since oxygen consumption (VO2) is proportional to $\mathrm{EE}$, the indirect calorimetry method is based on respiratory exchange. ${ }^{52}$

In indirect calorimetry, the participant wears a mask and carries the equipment necessary for the analysis of expired air to measure VO2 during physical activity, performed in an environment with controlled humidity, luminosity and temperature. The program that analyzes inspired oxygen and exhaled carbonic gas is calibrated according to maufacturer's instructions. ${ }^{58}$ One disadvantage of this technique is that wearing the equipment will probably impact the performance of the physical activity (Hawthorne effect). In addition, this is a complicated and expensive method. ${ }^{66}$ In turn, direct calorimetry is based on the fact that all metabolic processes occurring in the organism produce and store heat, with the quantity of heat lost being proportional to EE. ${ }^{58}$ In the rooms where calorimetry is performed, it is possible to obtain precise EE measures, since the subjects are confined to a small space with controlled temperature, humidity and luminosity throughout the measuring time. ${ }^{67}$ Even under these conditions, the relationship between body temperature and EE may be altered by the level of physical conditioning. In these situations, the monitoring of body temperature is not adequate as the single measurement of EE, but may be useful as part of an integrated monitoring system. ${ }^{66}$

The gold standard for the "outdoor" measurement of EE is the "double-labeled water" method, which is based on the principles of indirect calorimetry. The process involves the intake of a dose of stable ${ }_{2} \mathrm{H}_{2} \mathrm{O}$ and $\mathrm{H}_{218} \mathrm{O}$ isotopes immediately followed by the measurement of the elimination of these isotopes in urine. The difference in isotope elimination 
rate is proportional to the metabolically produced $\mathrm{CO}_{2}$ $\left(\mathrm{VCO}_{2}\right)$, a result which is then used to calculate total $\mathrm{VO}_{2}$ and EE. ${ }^{68}$ This approach yields the mean EE occurring over a measuring period of 7 to 14 days. ${ }^{66}$ Although this method has already been used for different populations of pregnant women, ${ }^{59}$ it does not provide information about the patterns of activity and cannot be used to differentiate the intensity, duration and frequency of the activities evaluated. The high cost of the isotope, together with the need for mass spectrometry to analyze the urine, causes this method to be too costly for use in clinical practice. Thus, the method is more often used for validation in epidemiological studies. ${ }^{66}$

Advantages - precise measurement methods. ${ }^{69}$

Disadvantages- it is not useful for epidemiological studies since it inhibits the normal physical activity of the person and is too expensive to be applied to large populations. ${ }^{69}$

\section{Combination of Analytical Methods}

With good acceptability and practicality, questionnaires represent one of the subjective forms of assessment of physical activity most extensively used in epidemiological studies. ${ }^{22}$ However, their reliability is low since they can overestimate the levels of physical activity compared with objective measurements such as those obtained with an accelerometer or pedometer. ${ }^{24,25}$

A strategy for the reduction of errors during the use of self-answered physical activity questionnaires is to follow a conceptual structure consisting of six steps: ${ }^{70}$ determination of the need to measure physical activity; selection of an instrument; data collection; data analysis; development of a scoring system; interpretation of the data.

The literature is controversial regarding the possibility to validate questionnaires using objective tools such as an accelerometer of pedometer. In 2004, Chasan-Taber et $\mathrm{al}^{30}$ developed a specific questionnaire for pregnant women and, when attempting to validate it with the use of an accelerometer, they detected a low to moderate correlation between tools.

A study conducted on 48 pregnant women with gestational ages ranging from 26 to 28 weeks, to compare subjective and direct measurements, observed that the pedometer provides a reliable estimate of physical activity during pregnancy, whereas the International Physical Activity Questionnaire is less precise. ${ }^{71}$

In a study conducted on 59 women with a BMI of more than 25 , at the end of the first trimester of gestation, the women answered two different questionnaires, used an accelerometer for 7 consecutive days and then answered again the questionnaires. The authors concluded that the questionnaires overestimated the activities of moderate to vigorous intensity and presented a low capacity to discriminate between the activities of these intensities, whereas the measurements provided by the accelerometers proved to be acceptable and viable. ${ }^{39}$

Comparison of methods for the objective measurement of physical activity reveals that pedometers are devices of lower cost than accelerometer, they have the ability to record the number of steps taken and have varying degrees of sensitivity. In turn, accelerometers, available in different models, are of higher cost, since they can detect and record the real magnitude of acceleration, permitting the determination of the quality or intensity of movement. ${ }^{38}$ Their high cost is their most relevant disadvantage. ${ }^{25}$ The main advantages of these devices are their small size that permits a person to be monitored for long periods of time without interfering with normal movements, as well as their capacity to store data in a continuous manner. This permits analysis of the information regarding the patterns of activity over several days or weeks. ${ }^{38}$

A study conducted on 81 patients who performed selected tasks from six general categories (gardening, housework, job, family care, conditioning, and recreation) tested the validity of four movement sensors for measuring EE during physical activities of moderate intensity in field and laboratory environments. Energy expenditure was measured during each activity using a portable system, as well as three accelerometers and an electronic pedometer. The authors concluded that the movement sensors tend to overestimate EE during a walk. On the other hand, they may underestimate many other activities due to their inability to detect arm movements or types of exercise in an outdoor environment, representing limitations of these instruments. ${ }^{58}$

Different methods for the assessment of physical activity have advantages and limitations. However, in view of the fact that they provide complementary information, their joint use provides an appropriate assessment of the time, level and intensity of activity. ${ }^{72}$

\section{Conclusion}

All tools for the analysis of physical activity have limitations. Thus, it is necessary to establish the objectives of evaluation in an appropriate manner, as well as to determine their viability and cost-effectiveness for the population under study

\section{Declaration of Conflicting Interests}

The authors declare that they have no conflicts of interest that are directly relevant to the content of this article.

\section{References}

1 Gavard JA, Artal R. Effect of exercise on pregnancy outcome. Clin Obstet Gynecol 2008;51(02):467-480

2 Prather H, Spitznagle T, Hunt D. Benefits of exercise during pregnancy. PM R 2012;4(11):845-850, quiz 850

3 Gaston A, Cramp A. Exercise during pregnancy: a review of patterns and determinants. J Sci Med Sport 2011;14(04): 299-305

4 Evenson KR, Bradley CB. Beliefs about exercise and physical activity among pregnant women. Patient Educ Couns 2010; 79(01):124-129

5 Pescatello LS, Arena R, Riebe D, Thompson PD. ACSM's guidelines for exercise testing and prescription. 9th ed. Philadelphia: Lippincott Williams \& Wilkins; 2014

6 Barbanti V. O que é esporte? Rev Bras Ativ Fís Saúde. 2006;11(01): 54-58

7 Clapp JF III. Exercise during pregnancy. A clinical update. Clin Sports Med 2000;19(02):273-286 
8 ACOG Committee Opinion No. 650: Physical Activity and Exercise During Pregnancy and the Postpartum Period. Obstet Gynecol 2015;126(06):e135-e142

9 Tobias DK, Zhang C, van Dam RM, Bowers K, Hu FB. Physical activity before and during pregnancy and risk of gestational diabetes mellitus: a meta-analysis. Diabetes Care 2011;34(01): 223-229

10 McAuley SE, Jensen D, McGrath MJ, Wolfe LA. Effects of human pregnancy and aerobic conditioning on alveolar gas exchange during exercise. Can J Physiol Pharmacol 2005;83(07):625-633

11 Stafne SN, Salvesen KÅ, Romundstad PR, Eggebø TM, Carlsen SM, Mørkved S. Regular exercise during pregnancy to prevent gestational diabetes: a randomized controlled trial. Obstet Gynecol 2012;119(01):29-36

12 Dempsey JC, Butler CL, Williams MA. No need for a pregnant pause: physical activity may reduce the occurrence of gestational diabetes mellitus and preeclampsia. Exerc Sport Sci Rev 2005; 33(03):141-149

13 Brown W. The benefits of physical activity during pregnancy. J Sci Med Sport 2002;5(01):37-45

14 Clapp JF III, Kim H, Burciu B, Lopez B. Beginning regular exercise in early pregnancy: effect on fetoplacental growth. Am J Obstet Gynecol 2000;183(06):1484-1488

15 Barakat R, Pelaez M, Lopez C, Montejo R, Coteron J. Exercise during pregnancy reduces the rate of cesarean and instrumental deliveries: results of a randomized controlled trial. J Matern Fetal Neonatal Med 2012;25(11):2372-2376

16 Davies GA, Wolfe LA, Mottola MF, et al; SOGC Clinical Practice Obstetrics Committee, Canadian Society for Exercise Physiology Board of Directors. Exercise in pregnancy and the postpartum period. J Obstet Gynaecol Can 2003;25(06):516-529

17 ACOG Committee Obstetric Practice. ACOG Committee opinion. Number 267, January 2002: exercise during pregnancy and the postpartum period. Obstet Gynecol 2002;99(01):171-173

18 Negrato CA, Montenegro RM Jr, Mattar R, et al. Dysglycemias in pregnancy: from diagnosis to treatment. Brazilian consensus statement. Diabetol Metab Syndr 2010;2:27

19 American College of Sport Medicine. ACSM's guidelines for exercise testing and prescription. 6th ed. Philadelphia: Lippincott Williams \& Wilkins; 2000

20 American Diabetes Association. Standards of medical care in diabetes-2015: summary of revisions. Diabetes Care 2015;38 (Suppl 1):S4

21 National Institute for Health and Care Excellence [Internet]. Weight management before, during and after pregnancy. Public Health guideline (PH27). 2010 [cited 2016 Oct 10]. Avaliable from: https:// www.nice.org.uk/guidance/ph27/chapter/1-recommendations

22 Ainsworth BE, Haskell WL, Leon AS, et al. Compendium of physical activities: classification of energy costs of human physical activities. Med Sci Sports Exerc 1993;25(01):71-80

23 Evenson KR, Chasan-Taber L, Symons Downs D, Pearce EE. Review of self-reported physical activity assessments for pregnancy: summary of the evidence for validity and reliability. Paediatr Perinat Epidemiol 2012;26(05):479-494

24 Prince SA, Adamo KB, Hamel ME, Hardt J, Connor Gorber S, Tremblay M. A comparison of direct versus self-report measures for assessing physical activity in adults: a systematic review. Int J Behav Nutr Phys Act 2008;5:56

25 Beets MW, Bornstein D, Beighle A, Cardinal BJ, Morgan CF. Pedometer-measured physical activity patterns of youth: a 13-country review. Am J Prev Med 2010;38(02):208-216

26 Sternfeld B, Goldman-Rosas L. A systematic approach to selecting an appropriate measure of self-reported physical activity or sedentary behavior. J Phys Act Health 2012;9(Suppl 1):S19-S28

27 Schmidt MD, Freedson PS, Pekow P, Roberts D, Sternfeld B, Chasan-Taber L. Validation of the Kaiser Physical Activity Survey in pregnant women. Med Sci Sports Exerc 2006;38(01):42-50
28 Mâsse LC, Ainsworth BE, Tortolero S, et al. Measuring physical activity in midlife, older, and minority women: issues from an expert panel. J Womens Health 1998;7(01):57-67

29 Hui AL, Back L, Ludwig S, et al. Effects of lifestyle intervention on dietary intake, physical activity level, and gestational weight gain in pregnant women with different pre-pregnancy Body Mass Index in a randomized control trial. BMC Pregnancy Childbirth 2014; $14: 331$

30 Chasan-Taber L, Schmidt MD, Roberts DE, Hosmer D, Markenson G, Freedson PS. Development and validation of a pregnancy physical activity questionnaire. Med Sci Sports Exerc 2004; 36(10):1750-1760

31 Takito MY, Neri LCL, Benício MHD. [Evaluation of the reproducibility and validity of a physical activity questionnaire for pregnant women]. Rev Bras Med Esporte 2008;14(02):132-138 Portuguese

32 Silva FT, Araujo Júnior E, Santana EF, Lima JW, Cecchino GN, Silva Costa FD. Translation and cross-cultural adaptation of the Pregnancy Physical Activity Questionnaire (PPAQ) to the Brazilian population. Ceska Gynekol 2015;80(04):290-298

33 Adeniyi AF, Ogwumike OO. Physical activity and energy expenditure: findings from the Ibadan Pregnant Women's Survey. Afr J Reprod Health 2014;18(02):117-126

34 Chen KY, Janz KF, Zhu W, Brychta RJ. Redefining the roles of sensors in objective physical activity monitoring. Med Sci Sports Exerc 2012;44(01, Suppl 1):S13-S23

35 Chandonnet N, Saey D, Alméras N, Marc I. French Pregnancy Physical Activity Questionnaire compared with an accelerometer cut point to classify physical activity among pregnant obese women. PLoS One 2012;7(06):e38818

36 Baecke JA, Burema J, Frijters JE. A short questionnaire for the measurement of habitual physical activity in epidemiological studies. Am J Clin Nutr 1982;36(05):936-942

37 Fell DB, Joseph KS, Armson BA, Dodds L. The impact of pregnancy on physical activity level. Matern Child Health J 2009;13(05): 597-603

38 Hendelman D, Miller K, Baggett C, Debold E, Freedson P. Validity of accelerometry for the assessment of moderate intensity physical activity in the field. Med Sci Sports Exerc 2000;32(9, Suppl) S442-S449

39 Ainsworth B, Cahalin L, Buman M, Ross R. The current state of physical activity assessment tools. Prog Cardiovasc Dis 2015; 57(04):387-395

40 Ainslie P, Reilly T, Westerterp K. Estimating human energy expenditure: a review of techniques with particular reference to doubly labelled water. Sports Med 2003;33(09):683-698

41 Richardson CR, Newton TL, Abraham JJ, Sen A, Jimbo M, Swartz AM. A meta-analysis of pedometer-based walking interventions and weight loss. Ann Fam Med 2008;6(01):69-77

42 Freak-Poli RL, Cumpston M, Peeters A, Clemes SA. Workplace pedometer interventions for increasing physical activity. Cochrane Database Syst Rev 2013;(04):CD009209

43 Meijer GA, Westerterp KR, Verhoeven FM, Koper HB, ten Hoor F. Methods to assess physical activity with special reference to motion sensors and accelerometers. IEEE Trans Biomed Eng 1991;38(03):221-229

44 Crouter SE, Schneider PL, Karabulut M, Bassett DR Jr. Validity of 10 electronic pedometers for measuring steps, distance, and energy cost. Med Sci Sports Exerc 2003;35(08):1455-1460

45 Lubans DR, Morgan PJ, Tudor-Locke C. A systematic review of studies using pedometers to promote physical activity among youth. Prev Med 2009;48(04):307-315

46 Marshall SJ, Levy SS, Tudor-Locke CE, et al. Translating physical activity recommendations into a pedometer-based step goal: 3000 steps in 30 minutes. Am J Prev Med 2009;36(05):410-415

47 Ogilvie D, Foster CE, Rothnie H, et al; Scottish Physical Activity Research Collaboration. Interventions to promote walking: systematic review. BMJ 2007;334(7605):1204 
48 Kang M, Marshall SJ, Barreira TV, Lee JO. Effect of pedometerbased physical activity interventions: a meta-analysis. Res Q Exerc Sport 2009;80(03):648-655

49 Freak-Poli RL, Wolfe R, Walls H, Backholer K, Peeters A. Participant characteristics associated with greater reductions in waist circumference during a four-month, pedometer-based, workplace health program. BMC Public Health 2011;11:824

50 Clarke KK, Freeland-Graves J, Klohe-Lehman DM, Milani TJ, Nuss HJ, Laffrey S. Promotion of physical activity in low-income mothers using pedometers. J Am Diet Assoc 2007;107(06):962-967

51 Normand MP. Increasing physical activity through self-monitoring, goal setting, and feedback. Behav Interv 2008;23(04):227-236

52 Melanson EL, Knoll JR, Bell ML, et al. Commercially available pedometers: considerations for accurate step counting. Prev Med 2004;39(02):361-368

53 Bouten CV, Westerterp KR, Verduin M, Janssen JD. Assessment of energy expenditure for physical activity using a triaxial accelerometer. Med Sci Sports Exerc 1994;26(12):1516-1523

54 Crouter SE, Kuffel E, Haas JD, Frongillo EA, Bassett DR Jr. Refined two-regression model for the ActiGraph accelerometer. Med Sci Sports Exerc 2010;42(05):1029-1037

55 Puyau MR, Adolph AL, Vohra FA, Zakeri I, Butte NF. Prediction of activity energy expenditure using accelerometers in children. Med Sci Sports Exerc 2004;36(09):1625-1631

56 Plasqui G, Bonomi AG, Westerterp KR. Daily physical activity assessment with accelerometers: new insights and validation studies. Obes Rev 2013;14(06):451-462

57 Brage S, Wedderkopp N, Franks PW, Andersen LB, Froberg K. Reexamination of validity and reliability of the CSA monitor in walking and running. Med Sci Sports Exerc 2003;35(08):1447-1454

58 Bassett DR Jr, Ainsworth BE, Swartz AM, Strath SJ, O'Brien WL, King GA. Validity of four motion sensors in measuring moderate intensity physical activity. Med Sci Sports Exerc 2000;32 (9, Suppl)S471-S480

59 Butte NF, Ekelund U, Westerterp KR. Assessing physical activity using wearable monitors: measures of physical activity. Med Sci Sports Exerc 2012;44(01, Suppl 1):S5-S12

60 Bell R, Tennant PW, McParlin C, et al. Measuring physical activity in pregnancy: a comparison of accelerometry and self-completion questionnaires in overweight and obese women. Eur J Obstet Gynecol Reprod Biol 2013;170(01):90-95

61 Dishman RK, Washburn RA, Schoeller DA. Measurement of physical activity. Quest 2001;53(03):295-309

62 Livingstone MB. Heart-rate monitoring: the answer for assessing energy expenditure and physical activity in population studies? Br J Nutr 1997;78(06):869-871

63 Schrack JA, Zipunnikov V, Goldsmith J, Bandeen-Roche K, Crainiceanu CM, Ferrucci L. Estimating energy expenditure from heart rate in older adults: a case for calibration. PLoS One 2014;9(04): e93520

64 Leonard WR. Measuring human energy expenditure: what have we learned from the flex-heart rate method? Am J Hum Biol 2003; 15(04):479-489

65 Kang TH, Merritt CR, Grant E, Pourdeyhimi B, Nagle HT. Nonwoven fabric active electrodes for biopotential measurement during normal daily activity. IEEE Trans Biomed Eng 2008;55(01):188-195

66 Lagerros YT, Lagiou P. Assessment of physical activity and energy expenditure in epidemiological research of chronic diseases. Eur J Epidemiol 2007;22(06):353-362

67 Lamonte MJ, Ainsworth BE. Quantifying energy expenditure and physical activity in the context of dose response. Med Sci Sports Exerc 2001;33(6, Suppl)S370-S378, discussion S419-S420

68 Schoeller DA. Recent advances from application of doubly labeled water to measurement of human energy expenditure. J Nutr 1999;129(10):1765-1768

69 LaPorte RE, Montoye HJ, Caspersen CJ. Assessment of physical activity in epidemiologic research: problems and prospects. Public Health Rep 1985;100(02):131-146

70 Ainsworth BE, Caspersen CJ, Matthews CE, Mâsse LC, Baranowski $\mathrm{T}$, Zhu W. Recommendations to improve the accuracy of estimates of physical activity derived from self report. J Phys Act Health 2012;9(Suppl 1):S76-S84

71 Harrison CL, Thompson RG, Teede HJ, Lombard CB. Measuring physical activity during pregnancy. Int J Behav Nutr Phys Act 2011;8:19

72 Haakstad LA, Gundersen I, Bø K. Self-reporting compared to motion monitor in the measurement of physical activity during pregnancy. Acta Obstet Gynecol Scand 2010;89(06):749-756 